\title{
THE FREQUENCY OF THROMBOCYTOPENIA IN PATIENT WITH MALARIA PRESENTING TO KHYBER TEACHING HOSPITAL PESHAWAR, PAKISTAN
}

\author{
Hamza Ali Khan, Zakir Ullah Khan, Saleem Iqbal, Sadaqat Ali, Shah Umam, Ghulam Abbas \\ Department of Medicine, Khyber Teaching Hospital, Peshawar - Pakistan
}

\begin{abstract}
Objective: The aim of the current study is to determie the frequency of thrombocytopenia among patients with malaria presented to the Khyber Teaching Hospital, Peshawar.

Material and Methods: A descriptive cross-sectional study was conducted at the Medicine Department of Khyber Teaching Hospital, Peshawar from August 2018 to February 2019. A total of 95 malaria parasite (MP) positive cases were included in the study. The patients' demographic details and the hematological variables were recorded. Data was analyzed using SPSS Version 20.0 .
\end{abstract}

Results: Among 95 MP positive patients, 88 had Plasmodium vivax infection while 7 patients were suffering from Plasmodium falciparum malaria. Moreover, 89 (93.6\%) were found to have thrombocytopenia with majority having grade 1 thrombocytopenia (52.6\%), while leukopenia was seen among $29.5 \%$ of the cases and only $5.3 \%$ presented with leukocytosis. The level of Hemoglobin $(\mathrm{Hb})$ was normal in majority of the cases and only $27.4 \%$ had $\mathrm{Hb}<11.5 \mathrm{~g} / \mathrm{dl}$.

Conclusion: Thrombocytopenia is a common hematological finding among the patients suffering from malaria. Our study findings favor the diagnostic implications of thrombocytopenia as an indicator of acute malaria.

Keywords: Malaria, Plasmodium falciparum, Plasmodium vivax, Thrombocytopenia, Leukopenia,

This article may be cited as: Khan HA, Khan ZU, Iqbal S, Ali S, Umam S, Abbas G. The Frequency of Thrombocytopenia in patient with Malaria presenting to Khyber Teaching Hospital Peshawar, Pakistan. J Med Sci 2020 October;28(4):337-340

\section{INTRODUCTION}

Malaria is a widespread protozoal infection, globally claiming the lives of more than 435,000 people each year ${ }^{1}$. On the basis of World Malaria Report 2018 published for the year 2017, a total of 219 million cases of malaria were estimated for the year 2017. ${ }^{1}$ More recently, World Health Organization (WHO) reported 405,000 deaths due to malaria in 2018 and $67 \%$ of them were under-five children. $^{2}$ In view of the associated complications and the overall disease associated risk, timely diagnosis and treatment is essential. ${ }^{3,4}$ Microscopic examination of the blood smear remains the gold standard for malaria diagnosis. Though the procedure is inexpensive but it requires time and expertise, as the malaria parasites are mostly not visible at a glance and repeated examinations are required for accurate diagnosis. Other alternate diagnostic tests include polymerase chain reaction (PCR) and malarial

\section{Correspondence}

Dr. Hamza Ali Khan

Assistant Professor

Department of Medicine Khyber Teaching Hospital,

Peshawar - Pakistan

Email: hamzaalikhan48@yahoo.com

Cell: +92-333-9333841

Date received: $11-04-2020$

Date revised: $\quad 11-08-2020$

Date accepted: $12-11-2020$ antigen-based rapid diagnostic tests (RDTs) but these methods are expensive and they are not used in routine clinical practice. ${ }^{5,6}$ Majority of the malaria patients have hematological abnormalities; thrombocytopenia, leukopenia and anemia being the most common. ${ }^{7}$ Thrombocytopenia has been documented as the best-known indicator of malaria by several studies..$^{8-10}$ Kochar and colleagues in their study reported thrombocytopenia in $24.6 \%$ of malaria infected patients. ${ }^{11}$ Although the interconnection of thrombocytopenia and malaria has long being studied but the exact pathogenic mechanism of the co-existence is not yet clear. Malaria associated thrombocytopenia is multifactorial i.e. increased bleeding, high platelet activation and apoptosis are the common etiologies. ${ }^{12,13}$ Moreover, the malarial antigens generate immune complexes which remove the affected platelets by phagocytosis. ${ }^{14,15}$ The present study is aimed to determine the changes in the hematological parameters particularly the prevalence of thrombocytopenia among the patients with malaria who presented to the Department of Medicine Khyber Teaching Hospital, Peshawar.

\section{MATERIAL \& METHODS}

This descriptive, cross-sectional study was conducted at the Medicine Department of Khyber Teaching Hospital, Peshawar for duration of six months from 29th 
The Frequency Of Thrombocytopenia In Patient With Malaria Presenting To Khyber Teaching Hospital Peshawar, Pakistan.

August 2018 to 28th February 2019. A sample size of 95 was calculated using WHO sample size calculator $(95 \%$ $\mathrm{Cl} ; 10 \%$ margin of error by using a frequency of $43.47 \%$ for smear positive malaria). Both male and female malaria positive patients, either presenting to the outpatient department (OPD) or admitted to the hospital were enrolled in the study. The age range was set for recruitment in the study; the upper age limit was 60 years for both genders while the lower age limit was 14 years for males and 12 years for females. All patients with negative malaria on the peripheral blood film or those with co-existing bacterial infections, diagnosed with acute febrile illness, dengue fever, chronic liver disease (CLD), sepsis, disseminated intravascular coagulation (DIC), viral hepatitis, systemic lupus erythematosus (SLE) and malignancies were excluded from the study. Moreover, patients with history of bleeding disorders, diagnosed thrombocytopenia (of other etiology) or those involved in active drug consumption (fansidar, quinine, salphonamides, septran, thiazides, heparin, etc) or antimalarial drugs were also excluded. The study was conducted after obtaining ethical approval from the institutional ethical review committee. The purpose of the study was explained to the patients and written informed consent was taken from each patient before enrollment. The patient data including demographic details and clinical history were recorded in a proforma. Clinical investigations were carried out for each enrolled patient with positive malaria parasite on blood smear. The hematological variables were computed through $\mathrm{CBC}$ via hematology analyzer. The obtained data was analyzed using a statistical software SPSS version 20.0. Mean and standard deviation (SD) were calculated for all quantitative variables while the categorical variables were presented as frequencies and percentages.

\section{RESULTS}

Out of the total 95 malaria patients, 56 (58.9\%) were males and $39(41.1 \%)$ were females, with majority between 12 to 30 years of age $(67.4 \%)$ while $21.1 \%$ were 31 to 45 years of age and only $11.6 \%$ were 46 to 60 years old. Moreover, $50.5 \%$ of the enrolled patients belonged to Peshawar district while the remaining (49.5\%) were from other areas like Mardan and Oghi etc. Out of the total 95 malaria cases, 88 (92.6\%) were positive for Plasmodium vivax and 7 (7.4\%) patients had Plasmodium falciparum malaria. The hematological parameters were examined in each case; platelet count, WBC and $\mathrm{Hb}$ levels were recorded and it was found that $93.6 \%$ of the cases were having co-existing thrombocytopenia. In patients with low platelets, $52.6 \%$ were suffering from grade 1 thrombocytopenia followed by $27.4 \%$ grade $2,10.5 \%$ grade 3 and only $3.2 \%$ had grade 4 thrombocytopenia. The WBC count was also monitored to determine the frequency of leukopenia among malaria patients; $29.5 \%$ patients had $<4000$ WBC's /mm3. The Hb levels were fairly normal among majority of the cases $(72.6 \%)$ with only $27.4 \%$ had $\mathrm{Hb}<11.5 \mathrm{~g} / \mathrm{dL}$

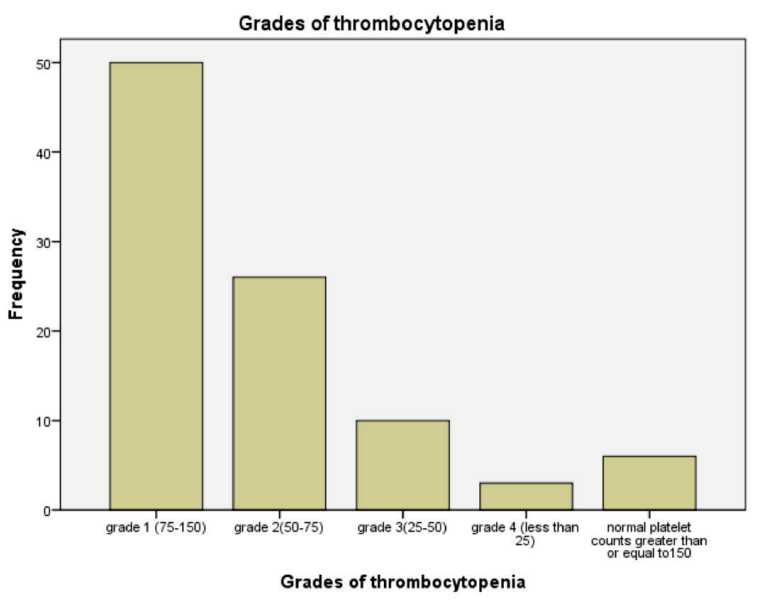

Fig 1: Showing frequency of thrombocytopenia

Table 1: Demographic characteristics of the study population $(n=95)$

\begin{tabular}{|c|c|c|}
\hline \multicolumn{2}{|c|}{ Variables } & n (\%) \\
\hline \multirow{2}{*}{ Gender } & Male & $56(58.9)$ \\
\cline { 2 - 3 } & female & $39(41.1)$ \\
\hline \multirow{2}{*}{ Residential Area } & Peshawar & $48(50.5)$ \\
\cline { 2 - 3 } & Others & $47(49.5)$ \\
\hline \multirow{2}{*}{ Age Group (Years) } & $12-30$ & $64(67.4)$ \\
\cline { 2 - 3 } & $31-45$ & $2(21.1)$ \\
\cline { 2 - 3 } & $46-60$ & $11(11.6)$ \\
\hline
\end{tabular}

Table 2: showing frequency of thrombocytopenia

\begin{tabular}{|c|c|c|}
\hline \multicolumn{2}{|c|}{ Variables } & $\mathbf{n}(\%)$ \\
\hline $\begin{array}{c}\text { MP Positive Case } \\
\text { Distribution }\end{array}$ & Plasmodium vivax & $88(92.6)$ \\
\cline { 2 - 3 } & Plasmodium falciparum & $7(7.4)$ \\
\hline $\begin{array}{c}\text { Grades of thrombocy- } \\
\text { topenia } \\
\text { (Platelet count per } \\
\text { mm3) }\end{array}$ & Grade 0 (>150,000) & $6(6.3)$ \\
\cline { 2 - 3 } & Grade 1 (75,000-150,000) & $50(52.6)$ \\
\cline { 2 - 3 } & Grade 2 (50,000-75000) & $26(27.4)$ \\
\cline { 2 - 3 } & Grade 3 (25000-50,000) & $10(10.5)$ \\
\hline \multirow{2}{*}{$\begin{array}{c}\text { WBC count (Per mm3 } \mu \mathrm{l}) \\
\text { or }\end{array}$} & Grade 4 (<25,000) & $3(3.2)$ \\
\cline { 2 - 3 } Hemoglobin (g/dl) & Normal (4000-11000) & $62(5.3)$ \\
\cline { 2 - 3 } & Less than 4000 & $28(29.5)$ \\
\cline { 2 - 3 } & Greater than 11000 & $5(5.3)$ \\
\cline { 2 - 3 } & Normal (11.5-17.5) & $69(72.6)$ \\
\cline { 2 - 3 } & Less than 11.5 & $26(27.4)$ \\
\hline
\end{tabular}

\section{DISCUSSION}

Malaria is one of the common causes of acute febrile illness in our country affecting almost all the blood components. Approximately $60 \%$ to $80 \%$ of the malaria cases have been reported with co-existing thrombocytopenia, while for anemia the association rate is $25 \%$. 16,17 The hematological estimations and parameters including platelet count, WBC count and $\mathrm{Hb}$ has been effective- 
The Frequency Of Thrombocytopenia In Patient With Malaria Presenting To Khyber Teaching Hospital Peshawar, Pakistan.

ly used among malaria patients in order to identify the variations and frequencies among the above mentioned parameters (thrombocytopenia, leucopenia and anemia). High frequency of thrombocytopenia was observed (93.6\%) by Patel and his colleagues among the enrolled MP positive patients. ${ }^{18}$ Consistent with our results, a local study conducted by Qurban and his colleagues reported $80.6 \%$ MP positive patients with thrombocytopenia. ${ }^{9}$ Moreover, the MP positive patients with vivax malaria are more likely to develop thrombocytopenia according to a Brazilian study. ${ }^{19}$

Thrombocytopenia was primarily thought to be associated with Plasmodium falciparum malaria but now the reported incidence rate is equal among both $P$. falciparum and P. vivax malaria or even more common in $P$. vivax malaria patients according to some authors. ${ }^{20} \mathrm{Re}$ gardless of the fact that thrombocytopenia is described as a complication of malaria, it is not considered as a severe instability on its own and as such no mortality risk is associated with it.. ${ }^{20}$ An Indian study ${ }^{21}$ reported higher incidence rate of thrombocytopenia among P. falciparum malaria cases $(83.80 \%)$ as compared to P. vivax $(74 \%)$, while a contradictory study by D.K. Kochar et al., reported more P. vivax cases with thrombocytopenia as compared to $P$. falciparum ${ }^{11}$. In comparison, our results also supported increased rate of thrombocytopenia among P. vivax malaria patients as majority of the enrolled malaria cases were of P. vivax (92.6\%) than P. falciparum (7.4\%). Similar results have been reported from Qatar and Venezuela ${ }^{24,}$ ${ }^{25}$. Besides thrombocytopenia, anemia and leukopenia were also observed among the study population. A total of $34.7 \%$ of the cases displayed changes in the WBC count, of which $29.5 \%$ being leukopenic while only $5.3 \%$ exhibited leukocytosis. The WBC decline rate is more pronounced in our study as compared to other parallel studies which reported $10 \%$ to $22.2 \%$ of leucopenia among malaria patients. ${ }^{21,22}$ Bashwari et al, from Saudi Arabia has reported anemia in $60 \%$ of the malaria cases, ${ }^{23}$ while comparatively only $27.4 \%$ of our MP positive patients were anemic. The presence of thrombocytopenia is not a distinguishing feature between the different species of malaria. In our study it was found that the thrombocytopenia was seen both in P. vivax and P. falciparum though it is more common in P. vivax infection. The results show high frequency of thrombocytopenia of various grades among the studied MP positive cases. The presence of thrombocytopenia in acute febrile patients and considering malaria on the top differential diagnoses will help in the prompt management of these patients. Our study had several limitations that must be kept in mind. Firstly, we had a small sample size and specific study settings and secondly, no control group was available for comparative analysis.

\section{CONCLUSION}

The current study has drawn clinical inferences that the presence of thrombocytopenia among the patients with acute febrile illness increases the probability of malarial disease. Hence, it is concluded that the platelet count serves as an important initial screening tool among patients with acute febrile illness.

\section{REFERENCES}

1. Directorate of Malaria Control. Pakistan Malaria Annual Report 2019.

2. World health organization (WHO). Malaria [Updated January 14,2020$]$.

3. Haslett C, Chilvers ER, Boon NA, Colledge R. Davidson's principles and practice of medicine.19th ed. Edinburgh: Churchill Livingstone; 2002.

4. Jadhav UM, Patkar VS, Kadam NN. Thrombocytopenia in malaria-correlation with type and severityof malaria. JAPI. 2004;52(615):8.

5. Khan SA, Ali W. Platelet count in malaria. Pak J Pathol 2008;19:86-88.

6. Tangpukdee N, Duangdee C, Wilairatana P, Krudsood S. Malaria diagnosis: a brief review. Korean J Parasitol. 2009;47(2):93.

7. Khan SJ, Khan FR, Usman M, Zahid S. Malaria can lead to Thrombocytopenia. Rawal Med J.2008;33(2):183-185

8. Lacerda MV, Mourão MP, Coelho HC, Santos JB. Thrombocytopenia in malaria: who cares? Memoriasdo Instituto Oswaldo Cruz. 2011;106:52-63.

9. Shaikh $\mathrm{QH}$, Ahmad SM, Abbasi A, Malik SA, Sahito AA, Munir SM. Thrombocytopenia in malaria. JCPSP. 2009;19(11):708-710.

10. Gill MK, Makkar M, Bhat S, Kaur T, Jain K, Dhir G. Thrombocytopenia in malaria and its correlation with different types of malaria. Annals of Tropical Medicine and Public Health. 2013;6(2):197.

11. Kochar DK, Das A, Kochar A, Middha S, Acharya J, Tanwar GS, et al. Thrombocytopenia in Plasmodium falciparum, Plasmodium vivax and mixed infection malaria: a study from Bikaner (Northwestern India). Platelets. 2010;21 (8):623-627.

12. Tanwar GS, Khatri PC, Chahar CK, Sengar GS, Kochar A, Tanwar G, et al. Thrombocytopenia in childhood malaria with special reference to $P$. vivaxmonoinfection: A study from Bikaner (Northwestern India). Platelets. 2012;23(3):211-216.

13. Fèvre EM, Wissmann BV, Welburn SC, Lutumba P. The burden of human African trypanosomiasis. PLoS neglected tropical diseases. 2008;2(12):e333.

14. Manickam $Y$, Chaturvedi R, Babbar P, Malhotra N, Jain V, Sharma A. Drug targeting of one or more aminoacyl-tRNA synthetase in the malaria parasite Plasmodium falciparum. Drug Discov. Today.2018;23(6):1233-1240.

15. World Health Organization. World malaria report 2018. Geneva. 
The Frequency Of Thrombocytopenia In Patient With Malaria Presenting To Khyber Teaching Hospital Peshawar, Pakistan.

16. Kreil A, Wenisch $\mathrm{C}$, Brittenham G. Thrombocytopenia in P falciparum malaria. Br J Hematol 2000; 109 (3): 534536.

17. Memon AR, Afsar S. Thrombocytopenia in hospitalized malaria patients. Pakistan Journal of Medical Sciences. 2006;22(2):141.

18. Patel U, Gandhi G, Friedman S, Niranjan S. Thrombocytopenia in malaria. J Natl Med Assoc 2004;96(9): 12121214.

19. Coelho HC, Lopes SC, Pimentel JP, Nogueira PA, Costa FT, Siqueira AM, et al. Thrombocytopenia in Plasmodium vivax malaria is related to platelets phagocytosis. PLoS One. 2013;8(5).

20. WHO. Severe falciparum malaria. Transactions of the Royal Society of Tropical Medicine and Hygiene. 2000;94(Supplement 1):S1-S90.

21. Patel P, Patel M, Gmait B, Modi J, Kevadiya S, Padsala $S$. Thrombocytopenia in malaria: correlation with various prevalent species. Int J Med Sci Public Health. 2013;2(4):946-950.

22. Taylor WR, Widjaja H, Basri H, Ohrt C, Taufik T, Tjitra E, et al. Changes in the total leukocyte and platelet counts in Papuan and non-Papuan adults from northeast Papua infected with acute Plasmodium vivax or uncomplicated Plasmodium falciparum malaria. Malaria Journal. 2008;7(1):259.

23. Bashwari LA, Mandil AM, Bahnassy AA, Alshamsi MA, Bukhari HA. Epidemiological profile of malaria in a university hospital in the eastern region of Saudi Arabia. Saudi Med J 2001; 22(2): 133-138.
24. Yousef Khan F, Lutof AK, Yassin MA, et al. Imported malaria in Qatar: a one year hospital-based study in 2005. Travel Medicine and Infectious Disease. 2009;7(2):111117.

25. Rodriguez-Morales AJ, Benitez JA, Arria M. Malaria mortality in Venezuela: focus on deaths due to Plasmodium vivax in children. J Trop Pediatr. 2008;54:94-101.

CONFLICT OF INTEREST: Authors declare no conflict of interest

GRANT SUPPORT AND FINANCIAL DISCLOSURE: NIL

\section{AUTHOR'S CONTRIBUTION}

Following authors have made substantial contributions to the manuscript as under

Khan HA: Concept, data Analysis, Approval of final draft

Khan ZU: Writing manuscript, Data analysis

Iqbal S: Statistical analysis, Critical review

Ali S:

Literature review

Umam S: Data collection

Abbas G: Bibliography, Proof reading

Authors agree to be accountable for all aspects of the work in ensuring that questions related to the accuracy or integrity of any part of the work are appropriately investigated and resolved. 